\title{
Genetic diversity and colony breeding structure in native and introduced ranges of the Formosan subterranean termite, Coptotermes formosanus
}

\author{
Claudia Husseneder • Dawn M. Simms • \\ Jennifer R. Delatte $\cdot$ Changlu Wang • \\ J. Kenneth Grace • Edward L. Vargo
}

Received: 3 February 2011 / Accepted: 9 August 2011/Published online: 23 August 2011

(C) The Author(s) 2011. This article is published with open access at Springerlink.com

\begin{abstract}
The Formosan subterranean termite, Coptotermes formosanus is recognized as one of the most important invasive pest species. Originating from China, C. formosanus has spread to many tropical and subtropical regions around the globe in the last 400 years, including Japan, Hawaii and the continental USA. Although the current distribution is well documented, information about the patterns of invasion and effects of introduction on the population genetics of this species is largely lacking. We analyzed the genetic structure of populations from two native populations (Guangdong and Hunan provinces, China) and two introduced populations (Maui and Kauai, Hawaii) using microsatellite genotyping. We also reanalyzed
\end{abstract}

C. Husseneder $(\bowtie)$. D. M. Simms · J. R. Delatte Department of Entomology, Louisiana State University Agricultural Center, 404 Life Sciences Bldg.,

Baton Rouge, LA 70803, USA

e-mail: chusseneder@agcenter.1su.edu

C. Wang

Department of Entomology, Rutgers, The State University of New Jersey, New Brunswick, NJ 08901, USA

J. K. Grace

Department of Plant and Environmental Protection Sciences, University of Hawaii at Manoa,

Honolulu, HI, USA

\section{E. L. Vargo}

Department of Entomology, North Carolina State University, Raleigh, NC 27695, USA published data of additional populations from China, Japan, Hawaii, and the continental USA. The population from Hunan, the earliest introduction outside of China (Japan) and the first introduction to the continental USA (South Carolina) showed little genetic similarity with any of the native or introduced populations investigated. However, populations from Oahu (HI), New Orleans (LA) and Rutherford County (NC) showed close similarity. In general, genetic patterns suggest multiple introductions to the USA, with, for example, two separate introductions to the island of Maui. Bottleneck effects were detected in almost all recent introductions (after 1940). All populations in the introduced range showed lower genetic diversity than those in the native range. However, this low genetic diversity did not result in the formation of polygynous supercolonies as has been described for other invasive termite and ant species.

Keywords Isoptera - Invasive insect .

Microsatellites · Bottleneck - Genetic diversity

\section{Introduction}

Relatively few termite species have established themselves as successful invaders with significant ecological and economic impact in their introduced ranges, despite the fact that termite species that nest in wood, such as drywood termites (Kalotermitidae) and subterranean termites (Rhinotermitidae), are 
easily transported to new locations by human trade and traffic. The most destructive of these species is the Formosan subterranean termite, Coptotermes formosanus, which has invaded many parts of the world including the Pacific Rim and the USA (Su and Tamashiro 1987; Su 2003) and is considered among the 100 worst invasive species in the world (Global Invasive Species Database 2010). The annual costs associated with damage repair and control of the Formosan subterranean termite are estimated to exceed $\$ 1$ billion (Pimentel et al. 2005).

Although the common name is derived from the first description of this termite species in 1909 from specimens collected on the island of Formosa, i.e., Taiwan (Shiraki 1909), it is commonly believed that the native range of the Formosan subterranean termite is the southeastern part of mainland China. This belief is based on the termitophilous beetles associated with Formosan subterranean termite colonies (Kistner 1985) and the high species diversity within the genus Coptotermes in this geographical area (Li 2000). The Formosan subterranean termite is found in 14 provinces/autonomous regions in southern China with a northern limit of $33^{\circ} 28^{\prime}$ and a western limit $104^{\circ} 35^{\prime}$ (Wang et al. 2002). The earliest known introduction of $C$. formosanus outside of the original native range was to Japan prior to the $1600 \mathrm{~s}$ (Vargo et al. 2003). Although officially collected in Hawaii in 1907 and reported in 1913 (Swezey 1914), C. formosanus was probably transported to the Hawaiian Islands earlier, presumably via the sandalwood trade from Canton, i.e., Guangdong, China (Yates and Tamashiro 1990). Newspaper articles indicate the presence of Formosan subterranean termites on the island of Oahu as early as 1869 ( $\mathrm{Su}$ and Tamashiro 1987; Yates and Tamashiro 1990). Introductions to other Hawaiian islands followed with the Island of Hawaii (1925), Kauai (1929), Lanai (1932), Maui (1933) and Molokai (1975) (Yates and Tamashiro 1990). The infestation on Maui and Lanai were purportedly eradicated, but a second introduction followed in the late 1940s or early 1950s (Yates and Tamashiro 1990). Since infestations on most of the Hawaiian Islands were originally concentrated around seaports, it is believed that the main transportation was by wooden ships, ship palettes, crates and other wooden material. Nowadays, however, infestations are found throughout most of Oahu and Kauai, and in several areas on
Maui and the other islands, which indicates continued spread and/or additional introductions.

Introductions of $C$. formosanus into the continental US have been associated with military ports receiving and storing equipment and supplies from the Pacific theater after World War II (Spink 1967). The first record of $C$. formosanus on the US mainland was a specimen collected from Charleston, South Carolina in 1957 (Chambers et al. 1988), followed by specimens from a shipyard in Houston, Texas in 1965 (Anonymous 1965). The Formosan subterranean termite was reported in New Orleans, Louisiana in 1966 (Spink 1967); however, the considerable infestation rate of buildings and trees suggests that C. formosanus had already been present in the region for several years prior to this report (Spink 1967). Once established, C. formosanus spread throughout the southeastern US. Its widespread but patchy distribution on the US mainland includes at least ten states: from North Carolina and Tennessee south to Florida on the East Coast, throughout the Gulf Coast into Texas and California on the West Coast (Woodson et al. 2001). Spread across state lines has been suggested to occur via the transport of infested railroad cross ties used in landscaping (Jenkins et al. 2002).

Although the putative dates of introduction and current distribution of $C$. formosanus are well documented, little is known about its invasion biology, including the origin and number of introductions within each region and the relationships among populations from the native and introduced ranges. Furthermore, the impact of introductions to new habitats on genetic diversity and colony structure of C. formosanus is largely unknown. Although the symbiont diversity does not seem to be affected by the introduction of $C$. formosanus to new habitats (Husseneder et al. 2010), it is conceivable that a loss of genetic diversity in introduced termite populations due to a limited number of founder colonies may have far reaching consequences. For example, in other social insects such as the red imported fire ant (Solenopsis invicta, Suarez et al. 1999), the Argentine ant (Linepithema humile, Giraud et al. 2002) and the big-headed ants (Pheidole megacephala, Fournier et al. 2009) it has been shown that loss of genetic diversity or genetic cleansing of recognition cues after introduction leads to a breakdown in nest mate recognition and the formation of large supercolonies 
in the introduced range that are able to dominate native species (e.g., Tsutsui and Suarez 2003). These findings have been suggested to explain invasion success of ants.

Like some invasive ant species (e.g., Solenopsis invicta, Ross and Keller 1998), colonies of C. formosanus have two breeding structures: simple families headed by a single pair of reproductives (analogous to monogyne ant colonies) and extended families headed by numerous reproductives in analogy to polygynous colonies in ants, except that in termites the reproductives are inbreeding neotenics produced within the nest (reviewed in Vargo and Husseneder 2009). The large foraging areas of some Formosan subterranean termite colonies extend to over $1,600 \mathrm{~m}^{2}$ (Messenger et al. 2005; Husseneder et al. 2005), and may be comparable to supercolonies in ants. Like invasive ants, populations of some invasive termite species, e.g., Reticuliterme flavipes and $R$. urbis have reduced genetic diversity and large colonies with exclusively extended family structures in the introduced range (Western Europe) (Dronnet et al. 2005; Leniaud et al. 2009, 2010).

In this study, we employed microsatellite genotyping to analyze the genetic structure of $C$. formosanus populations from the native (Guangdong and Hunan provinces, China) and introduced ranges (Kauai and Maui, Hawaii) to establish whether the colony and population genetic structure of the Formosan subterranean termite differs between native and introduced populations. We compare the results of this study to reanalyzed data from previously published C. formosanus populations from China, Japan, Oahu (HI) and the US mainland (Vargo 2003; Husseneder et al. 2005, 2008; Vargo et al. 2006) to identify potential factors that may facilitate invasiveness and identify possible routes of invasion and subsequent spread. Specifically we (1) describe the population genetic structure and relationships among native and introduced populations of $C$. formosanus, (2) test whether $C$. formosanus populations in the introduced range experienced genetic bottlenecks leading to reduced genetic diversity, and (3) compare the colony breeding structure among native and introduced $C$. formosanus populations to test the hypothesis that introduced populations predominantly consist of extended family colonies (in analogy to the large polygynous supercolonies found in some invasive ants and Reticulitermes species).

\section{Materials and methods}

Samples

At least 25-50 individuals per sample were collected in the field and immediately preserved in $95 \%$ ethanol. Samples from sites in Guangdong $(\mathrm{n}=20)$ and Hunan provinces $(n=22)$ were collected in the spring and summer of 2001 from pine stumps and logs. Samples from sites in Kauai $(\mathrm{n}=22)$ and Maui $(\mathrm{n}=18)$ were collected between 2000 and 2002 by pest management professionals from Mokihana Pest Control and Bowman Termite and Pest Control LLC, respectively, from infestation sites prior to treatment or from untreated monitoring stations (Maps in Fig. 1). Additional population genetic analyses were performed on previously published data (populations from Japan, the continental USA, Hawaii and China, Vargo et al. 2003, 2006; Husseneder et al. 2005, 2008) and were included in this study for comparison.

\section{Microsatellite genotyping}

DNA was extracted from individual termites from Guangdong province, Hunan province, Maui and Kauai using the DNeasy Tissue Kit (Qiagen Inc., Valencia, CA). At least 20 individuals from each sample were scored at eight microsatellite loci (Cf4:1A2-4, Cf4-4, Cf4-9A, Cf4-10, Cf8-4, Cf10-4, Cf10-5, Cf12-4, Vargo and Henderson 2000), which are routinely used for population genetic analyses of C. formosanus (e.g., Vargo et al. 2003; Husseneder et al. 2005) and did not show null alleles or linkage disequilibrium. A detailed description of the polymerase chain reaction and genotype scoring procedures can be found in Vargo (2000).

\section{Colony assignment}

Samples from the same geographic location were tested for significant genotypic differentiation using log-likelihood $G$-Statistics (FSTAT, Goudet 2001). $P$ values were obtained through permutations of the multilocus genotypes between each pair of samples and standard Bonferroni corrections were applied. If samples were significantly different from each other they were assigned to different colonies (Vargo et al. 2003; Husseneder et al. 2005, 2007). 

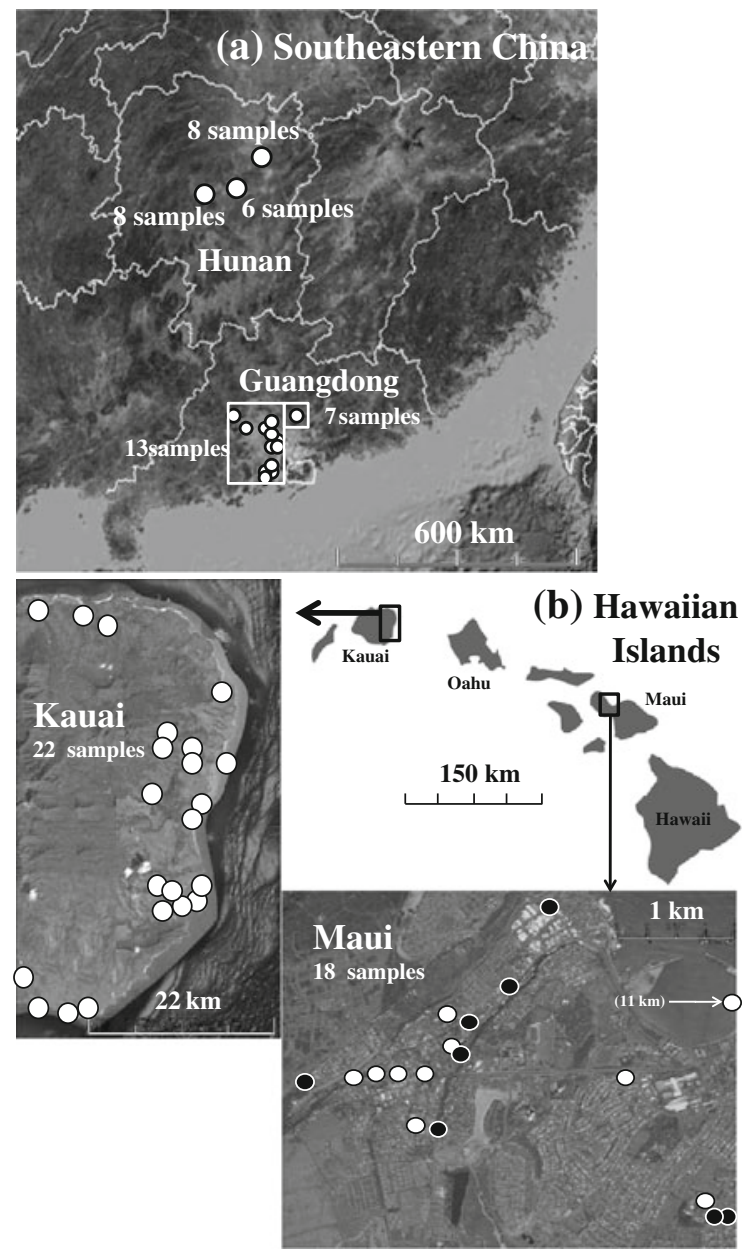

Fig. 1 Sample sites from Guangdong and Hunan province in southeastern China (a) and from the Hawaiian Islands, Kauai and Maui (b). Genetical analyses revealed two subpopulations in Maui (filled circle subpopulation 1; open circle subpopulation 2)

\section{Colony social organization}

We tested whether colonies were headed by a single pair of reproductives (simple family colonies) or multiple reproductives (extended family colonies) based on the frequencies and classes of worker genotypes (Vargo et al. 2003; Husseneder et al. 2005). Colonies were considered simple families if the classes of genotypes of the workers were consistent with those expected for the offspring of a single pair of parents and if the frequencies of the observed genotypes did not differ from the expected Mendelian ratios. Deviations from Mendelian ratios were determined between observed and expected genotypic frequencies at each locus by a $G$-test for goodness-of-fit. An overall $G$-value for each colony was obtained by summing the $G$-values across all eight loci. Colonies were considered extended families when they had more genotypes than possible for the offspring of a monogamous pair or the observed frequencies of the genotypes deviated significantly from those expected in simple families $(P<0.05$, $G$-test).

\section{$F$-statistics}

To analyze the population genetic structure and inbreeding at the levels of colony and population, hierarchical $F$-statistics were calculated using the methods of Weir and Cockerham (1984) as implemented in FSTAT. As previously reviewed (Vargo and Husseneder 2009), $F_{\mathrm{IC}}$ is the coefficient of inbreeding in individuals relative to their colony and reflects most clearly the colony's breeding system (Bulmer and Traniello 2002; Thorne et al. 1999; Bulmer et al. 2001). Empirical $F_{\text {IC }}$ values of colonies were compared among populations via independent samples $t$-test not assuming equal variances, and to values predicted by the computer simulations for different breeding systems (Bulmer et al. 2001; Thorne et al. 1999) by one-sample $t$-tests (SPSS 17.0). In addition, one-tailed one-sample $t$-tests were used to test $F_{\text {IC }}$ values across all loci for each extended family colony to establish the proportion of colonies for which $F_{\text {IC }}$ was significantly greater than zero (which would indicate assortative mating, mixing of colonies, and/or budding), not significantly different from zero (high number of neotenic reproductives) or significantly lower than zero (low number of reproductives) (Bulmer et al. 2001; Thorne et al. 1999).

From the worker genotypes present in each of the simple family colonies, the genotypes of the parents were reconstructed, and $F$-statistics for the reproductives were estimated from the inferred parental genotypes. We used likelihood calculations in KINSHIP 1.3.1 (Goodnight and Queller 1999, available at http://www.gsoftnet.us/GSoft.html) to test if parents were putative siblings, i.e., prior nest mates. The null hypothesis was that pairs were unrelated $(r=0)$, whereas the alternate hypothesis was that pairs were nest mates ( $r$ as determined by the average nest mate relatedness within all colonies of the respective 
population). Significance at the level of $P=0.05$ was determined by log likelihood tests using 10,000 series of pairs created at random.

Genetic structure of populations and isolation by distance

Ad hoc approximations of the number of subpopulations in each geographic sample (including the previously published populations: Vargo et al. 2003, 2006; Husseneder et al. 2005, 2008) were obtained based on a comparison of the penalized log likelihoods over independent simulation runs using STRUCTURE 2.3 (Evanno et al. 2005; Pritchard et al. 2000) with different numbers of assumed genetic clusters (K). Each colony was represented by one randomly chosen individual. All simulations were performed based on the admixture model with 100,000 runs in the data collection phase following a burn-in period of 100,000 runs. Three replications of simulations for each set of data and value of $\mathrm{K}$ confirmed that posterior probabilities were consistent across runs. Estimated membership coefficients in $\mathrm{K}$ clusters (degree of admixture) of each colony were calculated according to the algorithm of Pritchard et al. (2000) and plotted. Colonies from each geographical sample were probabilistically assigned to subpopulations in which they had predominant membership. If considerable structure was detected, datasets were divided into subsets and reanalyzed until the number of subpopulations was established. Confirmed subpopulations were then used as population genetic units of analysis rather than geographical populations based on collection localities. Matrix correlations between genetic distance and geographic distance were performed and tested for significance using Mantel tests (one sided p-values from 1,000 randomizations, IBD v. 1.52, Jensen et al. 2005) to test for isolation by distance.

\section{Detection of genetic bottlenecks}

We determined whether populations had experienced a recent genetic bottleneck using the program BOTTLENECK v. 1.2.02 (Piry et al. 1999). Bottlenecks were detected based on the fact that a bottleneck reduces allele numbers faster than heterozygosity, which leads to the observed heterozygosity being greater than the heterozygosity expected from the number of alleles present. Tests were performed using datasets that were resampled five times and contained one randomly chosen individual per colony to avoid bias by intracolonial relatedness. Individual genotypes were tested for heterozygote excess across loci using a Wilcoxon sign-rank test under different mutation models (infinite allele model, two-phased model of mutation, Piry et al. 1999).

\section{Genetic diversity of populations}

We performed rarefaction analyses on the samples collected for this study, and on previously published microsatellite data (Vargo et al. 2003, 2006; Husseneder et al. 2005, 2008), using EstimateS Win820 (Colwell et al. 2004) to compare genetic diversity among populations despite unequal numbers of colonies sampled and assess whether sampling effort was sufficient to capture the genetic diversity. Alleles with frequencies $\geq 5 \%$ in colonies were counted as present. The order of sampled colonies of each population was randomized 100 times. The observed number of alleles in each population was calculated using Mao Tau (Colwell et al. 2004). Allele numbers and their variance (95\% confidence interval) were plotted for each population as a function of the number of colonies sampled. We interpolated for the smallest number of colonies sampled to be able to compare allelic richness independent of sample size. The non-parametric incidence-based estimator (ICE) of expected allele richness, based on the numbers of singletons and doubletons in each sample (Colwell and Coddington 1994), was used to estimate the number of total alleles. In addition to allelic richness, genetic diversity of each population was measured with two indices commonly used in population biology: the Shannon index, which weighs both allele number and frequency and has a scale between 0 (low diversity) and $\sim 4.6$ (high diversity), and the Simpson index, which is strongly influenced by frequency since it reflects the likelihood that two alleles randomly drawn from the same sample are different (Colwell et al. 2004). To compare all native to all introduced populations and assess whether sampling effort at the population level was sufficient, rarefaction analyses were also performed with populations, instead of colonies, as sample units. Significant differences were established by non-overlapping 95\% confidence intervals of the rarefaction curves and non-parametric tests (SPSS 17.0). 


\section{Results}

Colony assignment, population structure and isolation by distance

The 20 samples collected from Guangdong province (Fig. 1a) belonged to 19 different colonies. Although colonies were dispersed over a range of $200 \mathrm{~km}$, no substructure, and only weak isolation by distance $\left(R^{2}=0.18, P=0.007\right)$ was detected in the population. The 22 samples collected from Hunan province (Fig. 1a) belonged to 21 colonies. STRUCTURE indicated the potential presence of multiple subpopulations ( $2-4$ clusters) among the samples from Hunan province. However, assignment of most colonies to any one of the clusters was weak $(<80 \%)$. Clusters were not congruent with the three geographic clusters of sample sites (Fig. 1a) and isolation by distance was weak $\left(R^{2}=0.19, P=0.001\right.$, over $\left.150 \mathrm{~km}\right)$. Therefore, we considered all Hunan colonies to belong to one population in the further analyses.

All 22 samples collected from Kauai (Fig. 1b) were assigned to different colonies. The population of Kauai showed no detectable substructure and no isolation by distance across $45 \mathrm{~km} \quad\left(R^{2}=0.03\right.$, $P=0.90)$. Similarly, each of the 18 samples from Maui (Fig. 1b) belonged to separate colonies. Colonies from Maui were collected well within $5 \mathrm{~km}$ and with no physical barriers to inhibit gene flow except one colony, which was separated by $11 \mathrm{~km}$ from the rest of the samples (Fig. 1b). Nevertheless, the Maui population showed weak but significant isolation by distance, which persisted even after removal of the distant colony from the dataset $\left(R^{2}=0.16\right.$, $P=0.005)$. Furthermore, results generated from STRUCTURE indicated the presence of two genetic clusters in the Maui population, with eight colonies assigned to the first subpopulation (Maui-1) and 10 colonies assigned to a second subpopulation (Maui-2, Fig. 1b). The majority (89\%) of colonies were strongly $(\geq 80 \%)$ assigned to one or the other subpopulation. Genetic separation was supported by 13 private alleles separating subpopulation Maui-2 from Maui-1 and two private alleles separating Maui1 from Maui-2. Separate analyses of each subpopulation, using STRUCTURE, did not reveal further substructures. Therefore, colonies from the two Maui subpopulations were treated separately in the following analyses. Interestingly, there was no obvious relationship between the genetic clusters and geographical location of the colonies (Fig. 1b).

We reanalyzed previously published data including populations from Japan (Vargo et al. 2003), Hawaii (Husseneder et al. 2008), the continental USA (Husseneder et al. 2005; Vargo et al. 2006) and one additional population from the native range (Guangzhou City, Guangdong province, Husseneder et al. 2008). No substructure or isolation by distance was detected in any of these populations, confirming that each geographical group of samples represented a single genetic population. Although Guangzhou City is located within Guangdong province, the samples from Guangzhou were collected years earlier from a rather localized urban area (Zhongshan University, Husseneder et al. 2008) and STRUCTURE indicated that the population from Guangzhou City largely belonged to a separate genetic cluster than the colonies from the rest of the province. The genetic distance between colonies from Guangzhou City and the other colonies from Guangdong province was small $\left(F_{\mathrm{ST}}=0.05\right)$, however, there were private alleles separating Guangzhou City (11 unique alleles) from the other Guangdong colonies (eight unique alleles). Therefore, we decided to treat Guangzhou City and Guangdong province samples as separate populations. Overall, the combined data set included three native populations and 10 introduced populations. Mean genetic distance among populations (global $F_{\mathrm{ST}}$ ) was $0.20(\mathrm{SD}=0.09)$. The mean genetic distance among populations within the native range $\left(F_{\mathrm{ST}}=0.09, \mathrm{SD}=0.05, \mathrm{n}=3\right.$ pairwise comparisons) was significantly lower than among introduced populations $\left(F_{\mathrm{ST}}=0.23, \mathrm{SD}=0.10, n=45\right.$; $P=0.020, Z=-2.31$, two-tailed Mann-Whitney $U$-test).

Evidence for genetic bottlenecks in recently introduced populations

The populations arising from the early introduction to Kauai (1929) and, prior to that, to Japan (1600s, Vargo et al. 2003) and Oahu (late 1800s), showed no evidence of a persistent bottleneck effect. Interestingly, strong evidence for a recent bottleneck was found in one Maui subpopulation (Maui-1), but not in the other (Maui-2). Four out of five resampled datasets for Maui-1 showed significant heterozygote excess under the infinite allele model, and 3 out of 5 
Fig. 2 Rarefaction analysis shows higher allelic richness in native populations. *Note that the allele number for Oahu is underestimated since the population was only genotyped at five out of eight loci

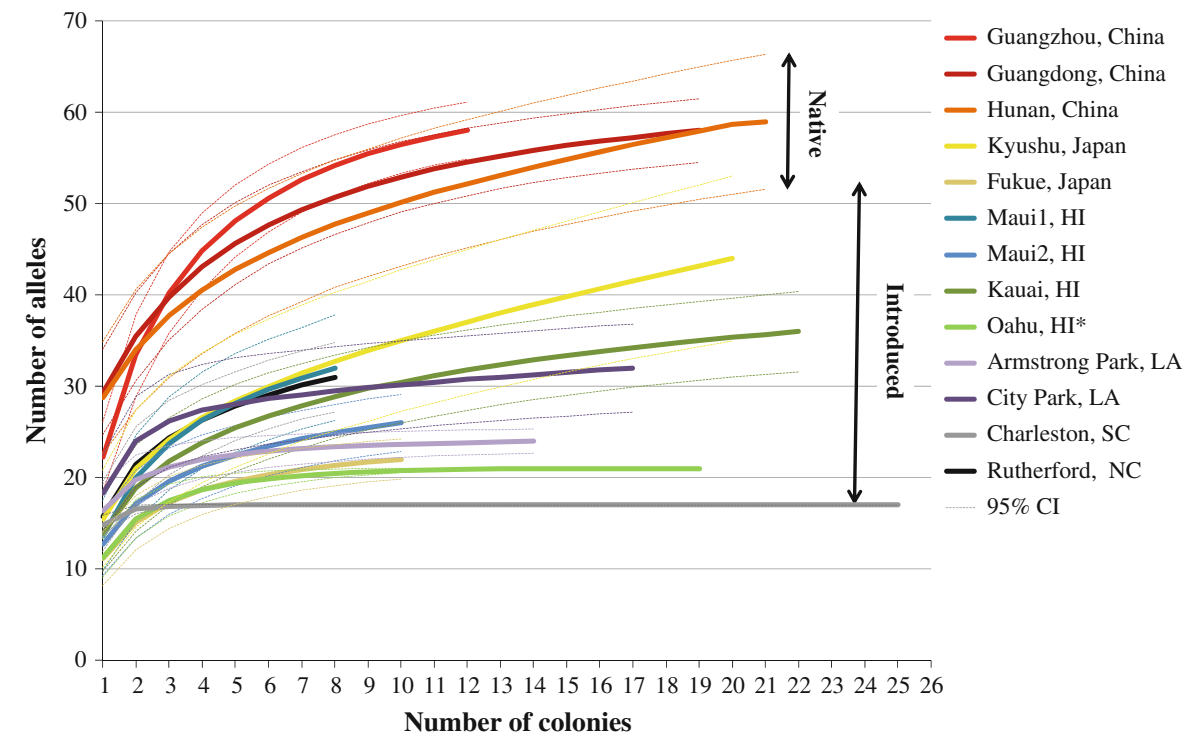

datasets showed heterozygote excess under the twophase model. Similar evidence for recent genetic bottlenecks was found in the populations from Armstrong Park (Husseneder et al. 2005) and City Park, in New Orleans, Louisiana, and Charleston, South Carolina (Vargo et al. 2006). All of these populations are known to be recent introductions (Charleston, SC: 1957; New Orleans, LA: 1966). Surprisingly, no bottleneck was detected in the recently introduced (1990) North Carolina population, which is likely due to the small sample size $(\mathrm{n}=8)$.

Genetic diversity within populations

Rarefaction analyses (Fig. 2; Table 1) showed that allelic richness, i.e., the number of alleles, was higher in native populations than in introduced populations. The difference was considered significant based on non-parametric tests $(P=0.011, Z=-2.542$, twotailed Mann-Whitney $U$-test) and the fact that $95 \%$ confidence intervals of the rarefaction curves of native and introduced populations did not overlap, except marginally for the curve for Kyushu, Japan. The curves of most populations leveled off and approached the estimated total allele number based on the ICE index. In most cases, over $80 \%$ of total alleles were captured (Table 1), indicating that the sample size was sufficient to measure allelic richness in the population. When allelic richness was interpolated for the lowest sample sizes (eight colonies each in Maui- 1 and in the North Carolina population), allelic richness remained almost two times higher in native populations compared to introduced populations $(P=0.011, Z=-2.535$, two-tailed Mann-Whitney $U$-test, Table 1$)$.

The higher genetic diversity in native populations was further confirmed using the Shannon and Simpson indices, which take both the allele number and frequency into account. Both indices showed that native populations have a significantly higher genetic diversity than introduced populations $[P=0.011$, $Z=-2.539$ (Shannon), $Z=-2.535$ (Simpson), two-tailed Mann-Whitney $U$-tests]. The same result was achieved when diversity indices were interpolated for a sample size of eight colonies via rarefaction.

Results from rarefaction analysis were also used to assess if the sampling effort was sufficient at the level of population (Muirhead et al. 2008). Rarefaction curves plotting allele numbers as a function of populations sampled, showed that samples from the ten introduced populations and the three native populations captured about $80 \%$ of the total allelic richness (Fig. 3). While the curve representing the introduced populations started to level-off, the curve of the native populations was not yet asymptotic, indicating that total allelic richness in the native range was probably underestimated and that the sampling effort needs to be increased across the native range. 
Table 1 Genetic diversity of Formosan subterranean termite populations from the native and introduced range

\begin{tabular}{|c|c|c|c|c|c|c|c|c|c|c|}
\hline & $\mathrm{N}$ & Allele\# & SD & ICE & SD & Allele\#/ICE (\%) & Shannon & SD & Simpson & SD \\
\hline \multicolumn{11}{|l|}{ Native range } \\
\hline \multirow[t]{2}{*}{ Hunan Province, China } & 8 & 46.31 & 3.57 & 56.76 & 6.22 & 82 & 3.60 & 0.07 & 38.77 & 2.87 \\
\hline & 21 & 59.00 & 3.77 & 71.19 & 0.00 & 83 & 3.67 & 0.04 & 36.22 & 1.52 \\
\hline \multirow[t]{2}{*}{ Guangdong Province, China } & 8 & 45.11 & 2.15 & 60.49 & 5.09 & 75 & 3.70 & 0.06 & 41.38 & 2.93 \\
\hline & 19 & 58.00 & 1.77 & 61.35 & 0.00 & 95 & 3.73 & 0.04 & 39.21 & 1.74 \\
\hline \multirow[t]{2}{*}{ Guangzhou City, China } & 8 & 54.18 & 1.72 & 62.51 & 4.51 & 87 & 3.75 & 0.08 & 46.33 & 4.52 \\
\hline & 12 & 58.00 & 1.60 & 62.21 & 0.00 & 93 & 3.78 & 0.08 & 44.91 & 3.86 \\
\hline \multicolumn{11}{|l|}{ Introduced range } \\
\hline \multirow[t]{2}{*}{ Kyushu, Japan } & 8 & 32.67 & 3.86 & 42.38 & 6.04 & 77 & 3.23 & 0.07 & 26.23 & 1.66 \\
\hline & 20 & 44.00 & 4.59 & 69.32 & 0.00 & 63 & 3.28 & 0.04 & 24.47 & 0.92 \\
\hline \multirow[t]{2}{*}{ Fukue, Japan } & 8 & 21.33 & 1.14 & 23.30 & 1.39 & 92 & 2.84 & 0.07 & 18.72 & 1.56 \\
\hline & 10 & 22.00 & 1.13 & 23.56 & 0.00 & 93 & 2.86 & 0.07 & 18.23 & 1.32 \\
\hline \multirow[t]{2}{*}{ Oahu, HI } & 8 & 20.45 & 0.24 & 21.40 & 1.20 & 96 & 2.87 & 0.05 & 19.90 & 1.31 \\
\hline & 19 & $21.00^{\mathrm{a}}$ & 0.00 & 21.00 & 0.00 & 100 & 2.91 & 0.03 & 18.45 & 0.69 \\
\hline Maui-1, HI & 8 & 32.00 & 2.94 & 38.56 & 0.00 & 83 & 3.16 & 0.10 & 25.82 & 2.66 \\
\hline \multirow[t]{2}{*}{ Maui-2, HI } & 8 & 24.91 & 1.58 & 28.26 & 1.81 & 88 & 2.97 & 0.07 & 21.05 & 1.32 \\
\hline & 10 & 26.00 & 1.59 & 29.10 & 0.00 & 89 & 2.98 & 0.06 & 20.40 & 1.13 \\
\hline \multirow[t]{2}{*}{ Kauai, HI } & 8 & 28.85 & 2.33 & 34.98 & 4.30 & 82 & 3.12 & 0.06 & 23.69 & 1.53 \\
\hline & 22 & 36.00 & 2.24 & 41.80 & 0.00 & 86 & 3.18 & 0.04 & 22.08 & 0.82 \\
\hline \multirow[t]{2}{*}{ Armstrong Park, LA } & 8 & 23.33 & 0.79 & 23.77 & 1.03 & 98 & 3.03 & 0.04 & 22.96 & 1.03 \\
\hline & 14 & 24.00 & 0.67 & 24.36 & 0.00 & 99 & 3.04 & 0.03 & 21.71 & 0.68 \\
\hline \multirow[t]{2}{*}{ City Park, LA } & 8 & 29.47 & 2.48 & 30.48 & 2.39 & 97 & 3.27 & 0.05 & 29.22 & 1.51 \\
\hline & 17 & 32.00 & 2.47 & 34.69 & 0.00 & 92 & 3.29 & 0.04 & 27.51 & 0.91 \\
\hline \multirow[t]{2}{*}{ Charleston, SC } & 8 & 17.00 & 0.00 & 17.00 & 0.02 & 100 & 2.81 & 0.01 & 18.39 & 0.24 \\
\hline & 25 & 17.00 & 0.00 & 17.00 & 0.00 & 100 & 2.82 & 0.00 & 17.30 & 0.11 \\
\hline Rutherford, NC & 8 & 31.00 & 1.94 & 35.32 & 0.00 & 88 & 3.16 & 0.09 & 26.01 & 2.39 \\
\hline
\end{tabular}

Allele numbers, incidence based estimator of total allele numbers (ICE), percentage of total alleles captured (Allele\#/ICE) and diversity indices (Shannon and Simpson) were calculated for the minimum number of colonies sampled per population $(\mathrm{n}=8)$ and for the total number of colonies sampled in each population via rarefaction analysis

${ }^{\text {a }}$ Note that the allele number for Oahu is underestimated since the population was only genotyped at five out of eight loci

\section{Breeding structure}

The $C$. formosanus populations from Guangdong and Hunan province and Kauai consisted predominantly of extended family colonies ( $\geq 86 \%$, Table 2 , Fig. 4 ). Similarly, about two-thirds of the colonies of Maui-1 were extended families. In contrast, Maui-2 consisted mainly of simple families (70\%). The comparison of all investigated populations to date showed that native populations of $C$. formosanus have significantly higher percentage of extended family colonies ( $P=0.007, Z=-2.454$, two-tailed Mann-Whitney $U$-test. Figure 4) when compared to introduced populations. However, this has to be confirmed by increasing the number of population samples from the native range.

Mean $F_{\text {IT }}$-values (inbreeding of individuals vs. population) in the Chinese populations were approximately half of those found in the Kauai and Maui populations, and relatedness within colonies was lower with the exception of the relatedness in extended families of Maui-2 (Table 2). However, when previously published populations were included in the analysis, there were no significant differences in $F_{\mathrm{IT}}, F_{\mathrm{ST}}, F_{\mathrm{IC}}$, and $r$-values between simple and extended families from the native and introduced range ( $P>0.05$, two-tailed Mann-Whitney $U$-tests). This was largely due to the high variability of these 


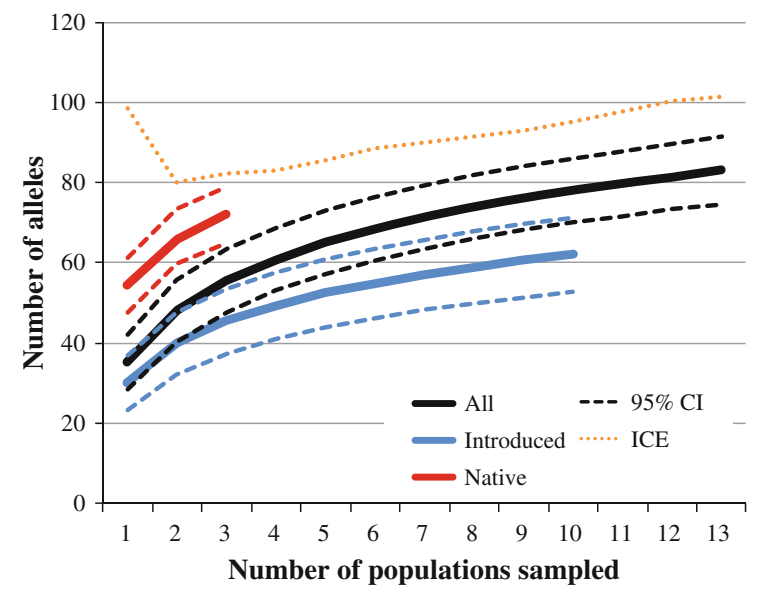

Fig. 3 Rarefaction analysis of number of alleles detected depending on number of populations sampled. The Incidence based estimator (ICE) of total allele numbers across native and introduced populations projects just over 100 alleles. Allele numbers in introduced populations start leveling off below 70 . This suggests that increasing the number of populations sampled from the introduced range is not likely to capture the projected total diversity. However, increasing the numbers of sampled populations in the native range likely would increase allele numbers towards the projected estimate

parameters across introduced regions and the low sample size of simple families in the native range.

Although the sample sizes of simple families were too small in the populations from Kauai and China to obtain robust statistics when comparing mean $F_{\text {IC }}$-values to the model, kinship analyses showed that $100 \%$ of parental pairs in simple family colonies from China, and one-third of simple families from Kauai, were nestmates. The simple families of the two Maui subpopulations had a mean $F_{\text {IC }}$-value that significantly differed from the model for colonies headed by outbred unrelated pairs (Table 2). This result was confirmed by KINSHIP analysis of the parental genotypes reconstructed from the worker genotypes of simple family colonies; all simple families on Maui were headed by nestmates. Such a high proportion of simple families headed by nestmates is rather the exception than the rule. The relatedness of pairs varies across the introduced range: from mainly unrelated outbred pairs in the South Carolina and Louisiana populations (Armstrong Park, City Park, New Orleans) to $30 \%$ nestmate pairs on Oahu, 33\% in the North Carolina population, $40 \%$ in the Kyushu population and $48 \%$ in the Fukue population.
Comparisons of mean $F_{\text {IC }}$-values of the extended families of the populations from Maui and Kauai to computer simulations did not reveal a clear picture due to the high variances and the positive mean (Table 2). Testing each individual colony showed high proportions of colonies with positive $F_{\text {IC }}$ values in the population of Kauai and in one of the Maui populations [Kauai: 4 of 19 (21\%) extended families; Maui2: 2 of $3(66 \%)]$. This is unprecedented, since only two other populations (South Carolina and Oahu) had colonies with positive $\mathrm{F}_{\mathrm{IC}}$ values and only with a low occurrence (4-5\%). The majority of $F_{\text {IC }}$ values in the extended family colonies from Kauai (14 of 19) and the two Maui subpopulations (5 of 8 ) were not significantly different from zero, and the colonies were therefore headed by a high number of neotenic reproductives. Only populations from the Hawaiian Islands and Kyushu contained extended families that were headed by a high number of reproductives. Extended families in most populations from the introduced range were headed by a low number of reproductives.

Eleven out of a total of 17 extended families in Guangdong province, and six of 18 extended families in Hunan province, had significantly negative $F_{\text {IC }}$-values $(P<0.05)$. The mean $F_{\text {IC }}$ values of extended families in both populations from China were significantly different from those predicted by computer simulations assuming a high number $(>10)$ of reproductives $(P<0.001$, Table 2$)$. Therefore, we conclude that most Chinese extended family colonies are headed by only a few neotenic pairs.

\section{Relationships among populations}

Colonies from the native population of Hunan province showed a rather uniform genetic pattern with all colonies assigned with $>60 \%$ to the same unique cluster (Fig. 5). This suggests that colonies from Hunan contributed little to the genetic make-up of other populations in the dataset. In contrast, colonies from Guangdong province and Guangzhou City are characterized by a genetic "patchwork" pattern of colonies containing up to 10 genetic clusters, indicating that these populations may have contributed to the genetic clusters in other populations in the dataset. For example, genetic characteristics from colonies of these two native populations occur in populations introduced to Oahu, Maui and Kauai. Interestingly, 
Table $2 F$-statistics and relatedness coefficients $(r)$ for workers of Formosan subterranean termite colonies from the native and introduced ranges and expected values for breeding systems, derived from computer simulations

\begin{tabular}{|c|c|c|c|c|c|}
\hline & $F_{\text {IT }}(S E)$ & $F_{\mathrm{CT}}(S E)$ & $F_{\mathrm{IC}}(S E)$ & pos. $F_{\mathrm{IC}}$ & $r(S E)$ \\
\hline \multicolumn{6}{|l|}{ Hawaiian Islands (introduced) } \\
\hline Kauai: simple family $(\mathrm{n}=3 ; 14 \%)$ & $0.57(0.11)$ & $0.65(0.09)$ & $-0.21(0.05)^{\mathrm{a}}$ & 0 & $0.83(0.06)$ \\
\hline Kauai: extended family $(\mathrm{n}=19 ; 86 \%)$ & $0.46(0.05)$ & $0.39(0.03)$ & $0.12(0.08)^{\mathrm{AE}}$ & 3 & $0.53(0.04)$ \\
\hline Maui 1: simple family $(\mathrm{n}=3 ; 38 \%)$ & $0.58(0.11)$ & $0.62(0.10)$ & $-0.07(0.17)^{\mathrm{ab}}$ & 0 & $0.78(0.09)$ \\
\hline Maui 1: extended family $(n=5 ; 62 \%)$ & $0.45(0.09)$ & $0.52(0.07)$ & $-0.13(0.12)^{\mathrm{ABCDE}}$ & 0 & $0.72(0.07)$ \\
\hline Maui 2: simple family $(\mathrm{n}=7 ; 70 \%)$ & $0.54(0.08)$ & $0.59(0.07)$ & $-0.12(0.05)^{\mathrm{b}}$ & 0 & $0.77(0.06)$ \\
\hline Maui 2: extended family $(\mathrm{n}=3 ; 30 \%)$ & $0.54(0.13)$ & $0.38(0.11)$ & $0.27(0.08)^{\mathrm{AE}}$ & 2 & $0.49(0.12)$ \\
\hline \multicolumn{6}{|l|}{ Southeast China (native) } \\
\hline Guangdong: simple family $(\mathrm{n}=2 ; 11 \%)$ & $0.23(0.09)$ & $0.40(0.08)$ & $-0.30(0.12)^{\mathrm{a}}$ & 0 & $0.67(0.10)$ \\
\hline Guangdong: extended family $(\mathrm{n}=17 ; 89 \%)$ & $0.18(0.04)$ & $0.35(0.02)$ & $-0.26(0.06)^{\mathrm{B}}$ & 0 & $0.60(0.03)$ \\
\hline Hunan: simple family $(\mathrm{n}=3 ; 14 \%)$ & $0.29(0.03)$ & $0.43(0.03)$ & $-0.23(0.05)^{\mathrm{a}}$ & 0 & $0.66(0.04)$ \\
\hline Hunan: extended family $(\mathrm{n}=18 ; 86 \%)$ & $0.27(0.04)$ & $0.35(0.02)$ & $-0.13(0.04)^{\mathrm{C}}$ & 0 & $0.55(0.02)$ \\
\hline \multicolumn{6}{|l|}{ Simulated breeding systems } \\
\hline \multicolumn{6}{|l|}{ (A) Simple family colonies with } \\
\hline (1) outbred unrelated pairs & 0.00 & 0.25 & $-0.33^{\mathrm{a}}$ & 0.50 & \\
\hline (2) inbred related pairs & 0.33 & 0.42 & $-0.14^{\mathrm{ab}}$ & 0.62 & \\
\hline \multicolumn{6}{|c|}{ (B) Extended family colonies with inbreeding among multiple neotenics } \\
\hline (1) $N f=N m=1, X=1$ & 0.26 & 0.65 & $-0.14^{\mathrm{CD}}$ & 0.55 & \\
\hline (2) $N f=2, N m=1, X=3$ & 0.52 & 0.59 & $-0.17^{\mathrm{BCD}}$ & 0.78 & \\
\hline (3) $N f=N m=10, X=1$ & 0.33 & 0.34 & $-0.01^{\mathrm{D}}$ & 0.51 & \\
\hline (4) $N f=200, N m=100, X=3$ & 0.33 & 0.34 & $0.00^{\mathrm{D}}$ & 0.50 & \\
\hline \multicolumn{6}{|c|}{ (C) Nest budding with interconnected daughter nests } \\
\hline (1) $N f=N m=1, X=3, P=0.5$ & 0.66 & 0.56 & $0.22^{\mathrm{E}}$ & 0.68 & \\
\hline (2) $N f=N m=1, X=3, P=0.9$ & 0.66 & 0.64 & $0.04^{\mathrm{A}}$ & 0.77 & \\
\hline (3) $N f=N m=100, X=3, P=0.9$ & 0.43 & 0.41 & $0.03^{\mathrm{A}}$ & 0.58 & \\
\hline
\end{tabular}

$n$ Number of colonies, $S E$ Standard error derived from jackknifing over colonies (or loci if sample size $\leq 3$ ), pos. $F_{\text {IC Number of }}$ colonies with $F_{\text {IC }}$ significantly greater than 0

One sample $t$-tests were performed using $F_{\mathrm{IC}}$-values across individual colonies. Significant differences, resulting from comparisons among empirical values for each of the breeding systems and to simulated values from the computer model are indicated by different letters (uppercase for extended families, lowercase for simple families)

For the simulated breeding systems, $X$ represents the number of generations of production of replacement reproductives within a colony; $N_{\mathrm{f}}$ and $N_{\mathrm{m}}$ represent the number of replacement females and males, respectively, produced per generation; $\mathrm{p}$ presents the proportion of workers originating from one of two intermixing nests

highly similar genetic patterns were found in the introduced populations from Oahu, Louisiana (especially City Park, New Orleans) and North Carolina, suggesting common ancestry to those introductions. The most likely source populations in the current database are populations from Guangdong province or Guangzhou City based on the low genetic differentiation among the populations $\left(F_{\mathrm{ST}}<0.09\right.$, Fig. 6). However, our database contains only a few samples from the native range and more definitive conclusions have to be drawn from more extensive studies.
Genetic links can also be found between Oahu and the other Hawaiian islands (Fig. 5), however, with larger genetic distances $\left(F_{\mathrm{ST}}=0.11\right.$ to Maui-1 and Kauai, 0.26 to Maui-2) than between Oahu and Louisiana populations $\left(F_{\mathrm{ST}}=0.04\right.$ for City Park, 0.05 for Armstrong Park) or the North Carolina population $\left(F_{\mathrm{ST}}=0.09\right)$. The genetic characteristics of Maui-1 colonies were found in colonies from Kauai and Oahu, suggesting shared ancestry or migration among the islands. In particular, two colonies from Kauai and one colony from Oahu were assigned to 


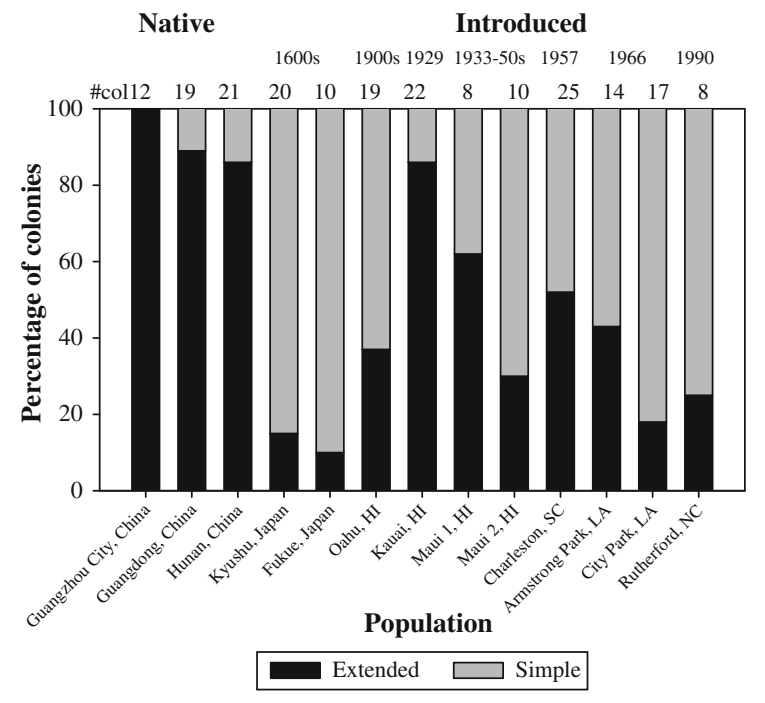

Fig. 4 Comparison of the percentage of simple versus extended family colonies between native and introduced populations

Maui-1 with $\geq 80 \%$, suggesting recent transport. Maui-2, however, was an independent introduction, with little intermixture with other populations in the dataset.

The two populations previously collected from Fukue and Kyushu in Japan (Vargo et al. 2003) shared little genetic characteristics with any of the native or introduced populations and were, thus, not a recent source or recipient of introduced colonies (Fig. 5). Interestingly, three colonies from Fukue were genetically assigned to the Kyushu population with membership coefficients $>95 \%$, indicating a recent transport of these colonies to Fukue from Kyushu or a related population. Vice versa, four of the Kyushu colonies were assigned to the Fukue population with membership coefficients $>80 \%$. Human transport probably is a factor in the gene flow, since geographical isolation of the Japanese islands (by approximately $100 \mathrm{~km}$ ) prevents spread by natural means. Like the Japanese populations, the earliest introduction to the continental USA, Charleston SC, was largely independent from the other populations studied so far. Its homogenous pattern suggests a single introduction, with a source unrelated to other populations in this study.

\section{Discussion}

The main focus points of our case study involving the invasion biology of the Formosan subterranean termite are: (1) identifying the origin of introduced populations to identify the main sources, routes and numbers of introductions, with the ultimate goal to devise preventative measures, (2) describing the genetic diversity of populations and colonies to assess viability and adaptability of the species in its invasive ranges, and (3) determining the breeding structures of colonies and possible genetic changes occurring after introduction.

Origin, routes and numbers of introductions of Formosan subterranean termites

Molecular markers have proven to be valuable in identifying source populations of invasive insects, including Mediterranean fruit flies (Davies et al. 1999), Asian longhorned beetle (Carter et al. 2010) and red imported fire ants (Caldera et al. 2008, Ascunce et al. 2011), among others. In invasive termite species of the genus Reticulitermes, the use of mitochondrial (mt) DNA sequences successfully demonstrated that the North American R. flavipes is the same species as the South American and European $R$. santonensis, and was thus introduced from North America to France and South America (Austin et al. 2005; Su et al. 2006). Microsatellite data, in conjunction with mtDNA data (Perdereau 2010) and cuticular hydrocarbons (Perdereau et al. 2010a) indicated that Louisiana was the likely origin to introductions of this species in France.

The lack of genetic variation in populations of C. formosanus has hindered the precise identification of source populations and routes of introduction via alloenzymes (Korman and Pashley 1991; Wang and Grace 2000) and mtDNA markers (Broughton and Grace 1994; Austin et al. 2006). For example, a study by Li et al. (2009) showed that the intraspecies variation of three mtDNA genes of $C$. formosanus ranged only from 0 to $0.3 \%$, in spite of global sampling. Suggested clades were separated by only up to $3 \mathrm{bp}$ differences. Even in the native range mtDNA variability of $C$. formosanus is low (Fang et al. 2008). Only one publication (Jenkins et al. 2002) reported a high degree of mtDNA variation in C. formosanus, but a subsequent study by Austin et al. (2006) concluded that this high variation may have been an artifact of sequencing or sequence alignment. Despite the lack of mtDNA variability, some important information was provided by mtDNA 

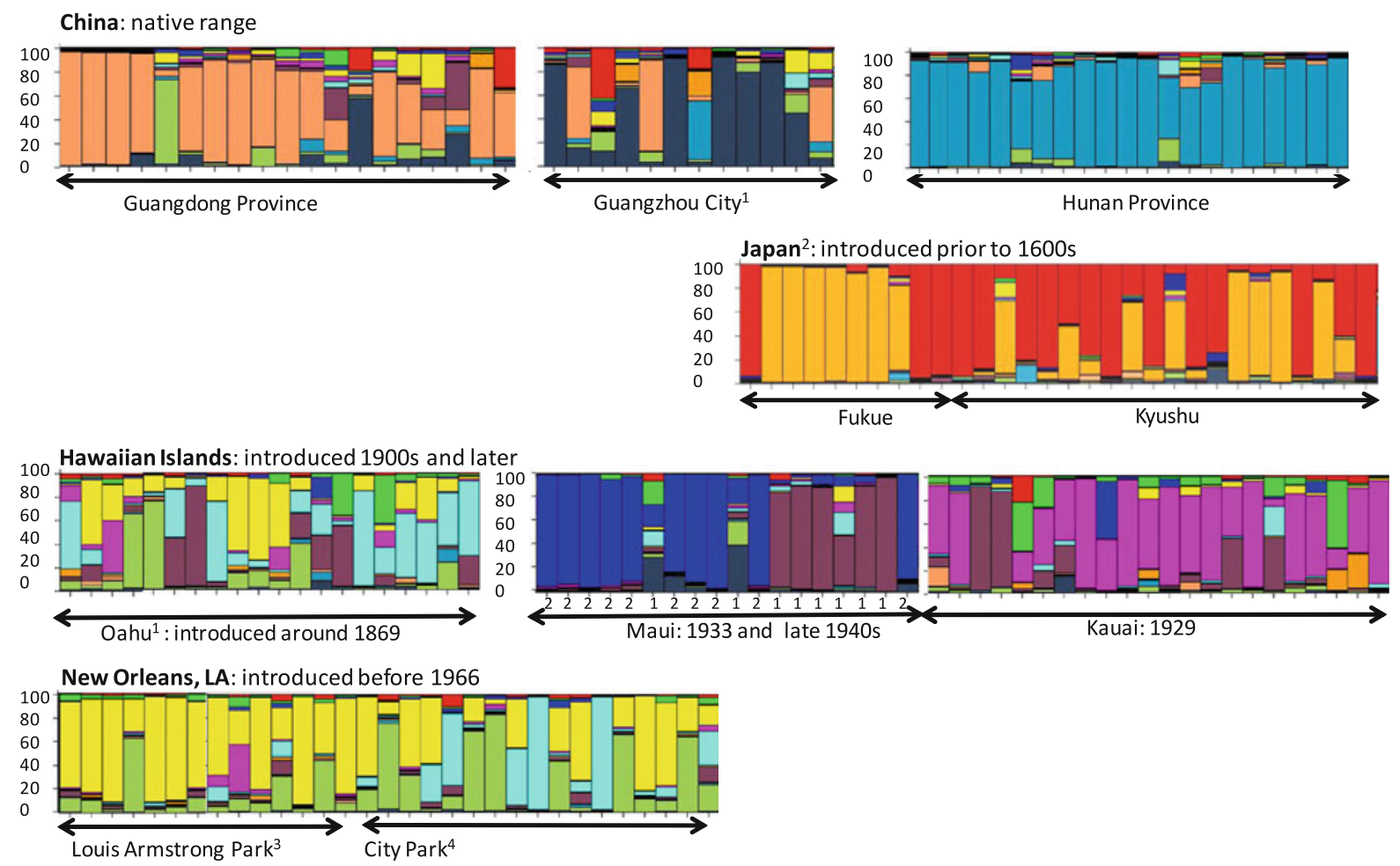

Rutherford, NC ${ }^{4}$ : introduced 1990

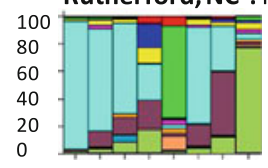

Fig. 5 Assignment of colonies to genetic clusters across all analyzed native and introduced populations. Data from previously published studies were reanalyzed and included: ${ }^{1}$ Husseneder et al. (2008), ${ }^{2}$ Vargo et al. (2003), ${ }^{3}$ Husseneder et al. (2005), ${ }^{4}$ Vargo et al. (2006). Columns represent colonies;

studies on large scale lineages of $C$. formosanus. For example, phylogenetic analyses of samples from the introduced and native range by Austin et al. (2006) resulted in two clades, one mainly comprised of several populations from China (Hong Kong, Guangzhou), Japan (Nagasaki) and Oahu, the other mainly of populations from the continental USA, including Louisiana (New Orleans, Lake Charles), North Carolina and South Carolina.

To overcome the limitations of low mtDNA variability in C. formosanus, we employed microsatellites in our studies, which have higher variability than mtDNA markers and a different mode of inheritance, increased the number of colonies sampled per population (compared to previous studies) and used probabilistic assignments of colonies to

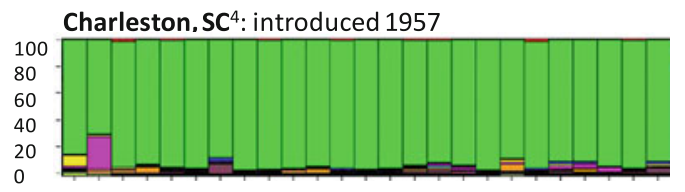

each color represent a different genetic cluster defined by STRUCTURE $(K=13)$. The colors in each column represent the likelihood with which a colony is assigned to each genetic cluster. Note that the red color in the Chinese populations is not the same as in the Japanese populations

populations to determine the degree of admixture within and between populations (Pritchard et al. 2000). We have shown that Hunan province is an unlikely source of origin for $C$. formosanus populations in the dataset due to the uniform and distinct genetic pattern of its populations, but we confirmed the close association between Guangdong province (including Guangzhou City) and Oahu, as suggested by Austin et al. (2006). This is not surprising considering historic shipping and immigration routes between Canton (Guangdong) and the Kingdom of Hawaii, with the main port in Honolulu (Gay 1967). Oahu's environmental conditions (warm temperatures, frequent rainfall, abundance of wooden constructions, and few competitors, predators, pathogens, etc.) are certainly favorable for the establishment and 


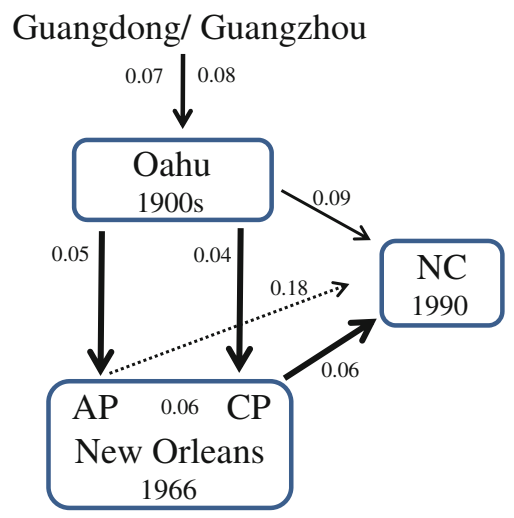

Fig. 6 Potential routes of invasion based on STRUCTURE analysis (Fig. 5) and genetic distances. Weight of arrows represents estimated genetic distance $\left(F_{\mathrm{ST}}\right.$ values adjacent to arrows). AP Armstrong Park, $C P$ City Park

spread of $C$. formosanus. Finding a close association between $C$. formosanus populations from Guangdong and Oahu, however, does not preclude the existence of additional source populations contributing to the colonization of the invasive range, e.g. from Hong Kong, Hainan and/or Taiwan (Fang et al. 2008; Li et al. 2009).

The main differences between our findings and those of Austin et al. (2006) were: (1) We could not confirm two distinct lineages separating the continental USA and Hawaii. While some of the continental (South Carolina) and Hawaiian populations (Maui-2) did not share many genetic characteristics with other populations in the dataset, there was clearly a genetic link between populations of Oahu, New Orleans and Rutherford, NC. It is well established that the Formosan subterranean termite was brought to the continental USA after World War II, via military retrograde from the Pacific Theater (LaFage 1987). Oahu was likely a staging area and hub for shipping wooden pallets, crates, etc. to ports in the USA, such as New Orleans. At least one well documented introduction to Armstrong Park, New Orleans was traced back to Camp Leroy Johnson, one of several military bases responsible for introducing Formosan subterranean termites to New Orleans after World War II (Spink 1967; Scott and Scott 1996). From New Orleans, C. formosanus may then have been transported to other areas in the southeast, like Atlanta (Jenkins et al. 2002) and North Carolina, via infested wooden materials, such as railroad ties. (2) The Japanese populations from Fukue and Kyushu were distinct from any of the native and introduced populations in our dataset, which is contrary to the placement of samples from Nagasaki in the same clade as samples from Guangzhou by Austin et al. (2006). This suggests that populations in Japan may have different origins. Some populations, including Nagasaki, may have originated from Guangzhou (or related populations in southeast China), which is supported by the observation that the same termitophilous beetle species are found in C. formosanus colonies originating both from southern China and southern Japan (Kistner 1985; Maruyama and Iwata 2002). The origin of other $C$. formosanus populations, including Fukue and Kyushu, has yet to be determined. Li et al. (2009) suggested that Taiwan (the original island of Formosa) may be the center of origin of the Formosan subterranean termite and the main source of introductions to Japan.

Several authors have suggested at least two introductions of $C$. formosanus to the US (Korman and Pashley 1991; Wang and Grace 2000; Vargo et al. 2006; Austin et al. 2006). The most conservative view of our dataset indicates at least five different sources of introductions. Populations from Oahu, New Orleans and North Carolina are similar (Vargo et al. 2006) and, therefore, were either introduced from a common source, or, more likely, were transferred among US locations after the original introduction (Fig. 6). The homogenous populations from South Carolina and Maui-1 each belong to genetic clusters very distinct from other populations in the dataset. Some colonies from Maui-2 and Kauai had similarities to colonies from Oahu, suggesting a common recent introduction to or migration among the Hawaiian Islands; however, the majority of colonies in these populations have their own distinct genetic signature.

The existence of different subpopulations colonizing the same area in Maui, one having gone through a recent bottleneck (Maui-1) and the other having reached equilibrium (Maui-2), can be interpreted in view of the introduction history. The first introduction to Maui happened in the early 1930s and the population was thought to be eradicated, while a second wave of invasion followed in the late 1940s or early 1950s (Yates and Tamashiro 1990). It is, however, conceivable that the earlier introduced population to Maui was not eradicated and has reached mutation-drift equilibrium (Maui-2), while the more recent introduction (Maui-1) still is subject 
to the effects of a bottleneck. This would be a more parsimonious explanation for the existence of two subpopulations than assuming a successful eradication and two subsequent new introductions.

The colonies of Maui-2 do not share much genetic admixture with other populations in the dataset and are thus of unknown origin. The genetic diversity of Maui-2 is low, suggesting that the population is based on only a few founder colonies or has gone through a bottleneck event (eradication effort) too long ago to be detected. In contrast, Maui-1 shows a bottleneck effect and was thus likely the more recent introduction of the two. The similarity of the genetic pattern of the Maui-1 population to that of colonies from the neighboring island of Oahu, suggests Oahu was the source of this introduction.

Geographical separation of the colonies of the two subpopulations of Maui does not exceed swarming distance (Messenger and Mullins 2005; Husseneder et al. 2006; Simms and Husseneder 2009), yet there is little admixture of the colonies. Apparently, interbreeding of Maui colonies is a rare event, as supported by the fact that all simple families in both subpopulations are headed by nestmate pairs, i.e., alates or neotenic pairs from the same colony. Alate swarms have been observed in Maui, but swarms are not likely to be the major form of colony propagation, because the lack of interbreeding among colonies suggests a low probability of incipient colonies reaching maturity. An unusually high proportion of extended family colonies of the presumably older introduction (Maui-2) showed positive $F_{\text {IC-values, }}$ similar to populations of Kauai and Oahu. Budding occurs when a portion of a colony gradually splits off and becomes a separate reproductive unit. During the process of budding genetically differentiated nests may still exchange workers (Husseneder et al. 1998)

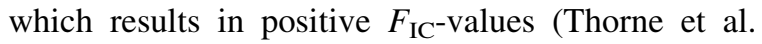
1999; Bulmer et al. 2001). Thus, budding may be a viable form of colony propagation in the Hawaiian islands; although this is rare in other $C$. formosanus populations (Vargo and Husseneder 2009). Propagation by budding, and the lack of successful colony foundation after swarming may explain the smallscale isolation by distance and the lack of admixture in the Maui populations.

Although microsatellite genotypes are capable of revealing even subtle substructures (e.g., subpopulations on Maui) and large scale gene flow (Oahu, New
Orleans, NC), more samples will be needed to complete the picture and pinpoint sources and routes of invasions for the remaining populations that did not share considerable genetic characteristics with any other population in the current dataset (i.e., South Carolina, Maui-2, Fukue, Kyushu). In this study, we focused on a part of the native range (Guangzhou City, Guangdong province) that is believed to be a major source of Formosan subterranean termite spread, due to a long-standing history of major trade routes. However, the overall lower genetic distance in these native populations as compared to the introduced populations suggests that a considerable number of potential source populations were not captured by this dataset. This was further supported by the fact that only a fraction of estimated allele numbers were represented in the investigated native populations (Fig. 3). Therefore, we are currently processing samples from additional historic trading and shipping centers in China, including Hong Kong, Fujian province, and Taiwan, among others. With the inclusion of additional populations from across the native range the likelihood of successful assignment to source populations is expected to increase significantly (Muirhead et al. 2008). Knowing the most likely origins and routes of introduction may facilitate the search for biological control agents and the development of cost-effective programs to prevent new introductions.

\section{Genetic diversity of populations}

Introduced populations frequently experience a genetic bottleneck due to transport of only a few individuals or colonies to a new location. Bottlenecks can only be detected across a few dozen generations (Luikart et al. 1998). Yet there is a lingering effect in the form of reduced genetic diversity (Holway et al. 2002; Tsutsui et al. 2000) unless repeated introductions from multiple, genetically distinct source populations counteract the effect of genetic bottlenecks connected to each single introduction. However, genetically diverse introduced populations, such as populations of the paper wasp in the USA (Johnson and Starks 2004), are the exception.

Introduced populations of Argentine ants (Suarez et al. 1999) and red imported fire ants (Krieger and Keller 1997, 1999) have low genetic diversity-in some cases with only $50 \%$ of the allelic richness of native populations (Tsutsui et al. 2000). Populations of the 
invasive termite $R$. flavipes also have only half of the allele numbers in introduced populations in France, compared to its native range (USA) (Dronnet et al. 2005; Vargo 2003; Vargo and Carlson 2006). The present study shows a similar reduction in allele numbers in introduced $C$. formosanus populations (Fig 2). Even if we combine the alleles found in all of the investigated introduced populations of the Formosan subterranean termite, the allelic richness in the introduced range ( 48 alleles) is $33 \%$ lower than in the native range (72 alleles), even though the allele numbers in the native range are an underestimate due to the limited number of populations sampled (Fig. 3). Although there were likely multiple independent introductions outside of China, even to the same geographical location (e.g., Maui), the effect of genetic bottlenecks (i.e., reduction in genetic diversity) with each introduction was not mitigated (Johnson and Starks 2004). Bottleneck events could still be detected in C. formosanus introductions recorded after the 1940s. Assuming that a newly founded termite colony matures within 5-8 years (Huang and Chen 1984), the time span of approximately 70 years since introduction would represent 8-14 generations, which falls into the typical timeframe in which bottlenecks are detectable (Luikart et al. 1998). Bottlenecks likely occurred in the older introduced populations, too, as evidenced by the reduced genetic diversity, but are no longer detectable. Reduced genetic diversity is predicted to have negative consequences, and should limit population growth, persistence and the ability of populations to adapt to changing selective pressures (Sakai et al. 2001). Nevertheless, invasive Reticulitermes and Coptotermes spp. persist, thrive and expand in their introduced ranges, despite reduced genetic variability.

\section{Colony breeding structure}

Reduced genetic diversity in introduced populations of social insects can have multiple ramifications concerning breeding structure. In invasive Hymenoptera, low genetic diversity is believed to be the reason for low intraspecific aggression, which in extreme cases leads to unicoloniality, i.e., the formation of large supercolonies that dominate the introduced range (Holway et al. 2002; Tsutsui et al. 2000, 2003; Breton et al. 2004; Suarez et al. 2008; Fournier et al. 2009). In addition, frequent occurrence of polygyny and colony propagation by budding could facilitate spread of invasive species after introduction (Tsutsui and Suarez 2003).

Only a few studies on genetic diversity and breeding structure in invasive termites have been conducted to date. These studies seem to corroborate the hypotheses derived from invasive ant species. For example, $R$. flavipes and $R$. urbis both have reduced genetic diversity and large extended family colonies with high numbers of neotenics in the introduced range of Western Europe (Dronnet et al. 2005; Leniaud et al. 2009, 2010). In their native range in North America, $R$. flavipes colonies are mainly simple families $(75 \%)$ or extended families $(22 \%)$ with few reproductives (Vargo and Husseneder 2009).

Furthermore, colony fusion, resulting in colonies headed by multiple unrelated reproductives, occurs in a greater rate in introduced populations of $R$. flavipes (up to $31 \%$, (Perdereau et al. 2010b) than in the native range (DeHeer and Vargo 2004), and, in general, populations with high proportions of extended family colonies have the highest rate of colony fusion (Bulmer et al. 2001; DeHeer and Kamble 2008). Fusion is facilitated by low levels of aggression among $R$. flavipes colonies. Incidental aggression has been reported in native North American populations (Shelton and Grace 1996), but aggression is largely lacking in the introduced range (Canada, France) where the highest rate of fusion occurs (Grace 1996; Perdereau et al. 2010b).

In contrast to invasive Reticulitermes spp., reduced genetic diversity in C. formosanus populations did not result in the predominance of extended families in the introduced range (Fig. 4). On the contrary, extended families seem to be predominant in the native range, although this result needs to be corroborated by including additional populations from the native range into the dataset. The breeding structure of colonies in the introduced range varies considerably among populations, with no correlation to the putative time of introduction (Fig. 4). Seven of the ten populations from the introduced range consisted mainly of simple families (Vargo et al. 2003, 2006; Husseneder et al. 2005, 2008). Solely, the population of Kauai showed a predominance of extended family colonies (86\%) comparable to that of native populations. The ratios of simple versus extended family colonies in introduced urban 
populations have been shown to shift over time, after disturbance or with reinvasion after treatment (Aluko and Husseneder 2007; Husseneder et al. 2007). Thus, the proportions of simple versus extended families in introduced populations are a reflection of variable ecological conditions, such as the degree to which the habitat is saturated with colonies, rather than a biological consequence of loss of genetic diversity or an adaptive pattern of establishment in a new area.

Interestingly, the Hawaiian populations showed high proportions of colonies with positive $F_{\text {IC }}$ values. Outside of Hawaii, only 1 of 13 extended family colonies in South Carolina (Vargo et al. 2006) showed positive $F_{\text {IC }}$ values, while none of the 47 extended family colonies from three native populations from China (this study and Husseneder et al. 2008) and none of the over 43 extended families from the introduced range of Louisiana (Husseneder et al. 2005, 2007; Vargo et al. 2006; Aluko and Husseneder 2007), North Carolina (Vargo et al. 2006) and Japan (Vargo et al. 2003) have shown significant positive $F_{\text {IC }}$ values.

Positive $F_{\text {IC }}$ values are caused by mixing of genetically different groups. If unrelated colonies fuse, like it has been shown for invasive Reticulitermes spp. (DeHeer and Vargo 2004; Perdereau et al. 2010b), relatedness among workers is expected to drop below 0.5 (Thorne et al. 1999; Bulmer et al. 2001), and worker genotypes would not be consistent with being the offspring of neotenics whose origin can be traced back to a single founder pair. However, all Hawaiian colonies with positive $F_{\text {IC }}$ showed high relatedness (0.52-0.72), and none had more than four alleles per locus. Thus, in contrast to fusion of unrelated Reticulitermes colonies in the introduced range, mixed C. formosanus colonies probably resulted from multiple groups of neotenic reproductives located in spatially separated reproductive centers within the colony, as would be expected if there was nest budding with interconnected daughter nests (Table 2, case C). Budding is known to occur in subterranean termites (Husseneder et al. 1998); however, it is not a wide-spread strategy for invasiveness in C. formosanus. Its occurrence is rather limited to certain geographical regions, such as Hawaii, probably due to ecological factors less conducive to the foundation of independent incipient colonies, as indicated by the high rate of nestmate pairs heading simple family colonies.
Fusion of unrelated colonies has not yet been observed in C. formosanus and is thus a rare event if it occurs at all in areas that have been sampled. In contrast to the above mentioned invasive ant and Reticulitermes species, reduced genetic diversity in the introduced range did not lead to a breakdown in nestmate recognition and intercolonial aggression of Formosan subterranean termites. Although aggression among C. formosanus colonies is variable in the introduced (Husseneder and Grace 2001; Shelton and Grace 1996) and native ranges (Husseneder, Vargo pers. observation) independent of breeding structure, colony integrity is typically maintained even with low aggression (Husseneder et al. 2005; Messenger and Su 2005).

In conclusion, the invasion success of the Formosan subterranean termite cannot be attributed to a breakdown in nest mate recognition and a shift to unicoloniality in introduced populations, as previously found in some highly invasive ants and termite species. There are, however, multiple, not mutually exclusive characteristics of Formosan subterranean termite biology that could facilitate invasiveness. For example, since nests are hidden in wooden material, colony propagules are protected from predation, are easily transported by human trade and traffic, and can usually remain undetected until the infestation has already spread (Spink 1967). Wood, as a food source, is almost unlimited and since efficient digestion of wood requires a special complement of gut symbionts (reviewed in Husseneder et al. 2010), there is limited competition for food. Multiple reproductive strategies, including dispersal by swarming or budding (although not frequently observed), the high fecundity of queens, the ability to produce neotenics after death of the colony founders, etc. (Vargo and Husseneder 2009), might allow populations to adapt and compete in a wide range of environmental conditions. However, these characteristics are true for many termite species, while only a few are truly successful invaders. What sets Formosan subterranean termites apart from most non-invasive termite species is the association with human activities and urban environments. In fact, even in their native range, Formosan subterranean termites are most easily found in areas inhabited or disturbed by humans (Vargo, Husseneder pers. observation). It has been previously shown for birds and other vertebrates that human association 
facilitates range expansion and invasiveness (Newsome and Noble 1986, Ehrlich 1989).

Acknowledgments We thank Mokihana Pest Control of Kauai and Bowman Termite and Pest Control LLC of Maui for providing samples and Julian Yates for introducing us to the respective termite control companies. Warren Booth gave helpful technical assistance and offered many suggestions on the manuscript. We thank Sue Garner for assisting with DNA extraction. We also thank Amit Sethi, Lane Foil and the anonymous reviewers for providing valuable comments on earlier drafts of this manuscript. This work was supported by grants from USDA-TSTAR to JKG, CH and ELV administered by the College of Tropical Agriculture \& Human Resources, University of Hawaii at Manoa, and USDA-ARS cooperative agreements and funds from the state of Louisiana to $\mathrm{CH}$.

Open Access This article is distributed under the terms of the Creative Commons Attribution Noncommercial License which permits any noncommercial use, distribution, and reproduction in any medium, provided the original author(s) and source are credited.

\section{References}

Aluko GA, Husseneder C (2007) Colony dynamics of the Formosan subterranean termite in a frequently disturbed urban landscape. J Econ Entomol 100:1037-1046

Anonymous (1965) Formosan subterranean termite-Texas. US Dep Agric Coop Econ Insect Rep 15:907-908

Ascunce MS, Yang C-C, Oakey J, Calcaterra L, Wu W-J, Shih C-J, Goudet J, Ross KG, Shoemaker D (2011) Global invasion history of the fire ant Solenopsis invicta. Science 25:1066-1068

Austin JW, Szalanski AL, Rudolf HS, Messenger MT (2005) Genetic variation of Reticulitermes flavipes (Isoptera: Rhinotermitidae) in North America: applying the mitochondrial rRNA 16S gene. Ann Entomol Soc Am 98:980-988

Austin JW, Szalanski AL, Scheffrahn RH, Messenger MT, McKern JA, Gold RE (2006) Genetic evidence for two introductions of the Formosan subterranean termite, Coptotermes formosanus (Isoptera: Rhinotermitidae), to the United States. Fla Entomol 89:183-193

Breton J, Delabie J, Chazeau J, Dejean A, Jourdan H (2004) Experimental evidence of large-scale unicoloniality in the tramp ant Wasmannia auropunctata (Roger). J Insect Behav 17:263-271

Broughton RE, Grace JK (1994) Lack of mitochrondrial DNA variation in an introduced population of the Formosan subterranean termite (Isoptera: Rhinotermitidae). Sociobiology 24:121-126

Bulmer MS, Traniello JFA (2002) Foraging range expansion and colony genetic organization in the subterranean termite Reticulitermes flavipes (Isoptera: Rhinotermitidae). Environ Entomol 31:293-298

Bulmer MS, Adams ES, Traniello JFA (2001) Variation in colony structure in the subterranean termite Reticulitermes flavipes. Behav Ecol Sociobiol 49:236-243
Caldera E, Ross K, DeHeer C, Shoemaker D (2008) Putative native source of the invasive fire ant Solenopsis invicta in the USA. Biol Invasions 10:1457-1479

Carter M, Smith M, Harrison R (2010) Genetic analyses of the Asian longhorned beetle (Coleoptera, Cerambycidae, Anoplophora glabripennis), in North America, Europe and Asia. Biol Invasions 12:1165-1182

Chambers DM, Zungoli PA, Hill HSJ (1988) Distribution and habitats of the Formosan subterranean termite (Isoptera: Rhinotermitidae) in South Carolina. J Econ Entomol 81:1611-1619

Colwell RK, Coddington JA (1994) Estimating terrestrial biodiversity through extrapolation. Philos Trans Biol Sci 345:101-118

Colwell RK, Mao CX, Chang J (2004) Interpolating, extrapolating, and comparing incidence-based species accumulation curves. Ecology 85:2717-2727

Davies N, Villablanca FX, Roderick GK (1999) Bioinvasions of the medfly Ceratitis capitata: source estimation using DNA sequences at multiple intron loci. Genetics 153:351-360

DeHeer CJ, Kamble ST (2008) Colony genetic organization, fusion and inbreeding in Reticulitermes flavipes from the Midwestern US. Sociobiology 51:307-325

DeHeer CJ, Vargo EL (2004) Colony genetic organization and colony fusion in the termite Reticulitermes flavipes as revealed by foraging patterns over time and space. Mol Ecol 13:431-441

Dronnet S, Chapuisat M, Vargo EL, Lohou C, Bagneres AG (2005) Genetic analysis of the breeding system of an invasive subterranean termite, Reticulitermes santonensis, in urban and natural habitats. Mol Ecol 14:1311-1320

Ehrlich PR (1989) Attributes of invaders and invading processes: vertebrates. In: Drake JA, DiCastri F, Groves RH, Kruger FJ, Mooney HA, Rejmánek M, Williamson MH (eds) Biological invasions: a global perspective. Wiley, New York, pp 315-328

Evanno G, Regnaut S, Goudet J (2005) Detecting the number of clusters of individuals using the software structure: a simulation study. Mol Ecol 14:2611-2620

Fang R, Huang L, Zhong JH (2008) Surprising low levels of genetic diversity of Formosan subterranean termites in south China as revealed by the COII gene (Isoptera: Rhinotermitidae). Sociobiology 51:1-20

Fournier D, De Biseau JC, Aron S (2009) Genetics, behaviour and chemical recognition of the invading ant Pheidole megacephala. Mol Ecol 18:186-199

Gay FJ (1967) A world review of introduced species of termites: CSIRO Melbourne, Australia. Bull 286:1-88

Giraud T, Pedersen JS, Keller L (2002) Evolution of supercolonies: the Argentine ants of southern Europe. Proc Natl Acad Sci USA 99:6075-6079

Global Invasive Species Database (2010) http://www.issg.org

Goodnight KF, Queller DC (1999) Computer software for performing likelihood tests of pedigree relationship using genetic markers. Mol Ecol 8:1231-1234

Goudet J (2001) FSTAT, a program to estimate and test gene diversities and fixation indices (version 2.9.3). Available from http://www.unil.ch/izea/softwares/fstat.html

Grace JK (1996) Absence of overt agonistic behavior in a northern population of Reticulitermes flavipes (Isoptera: Rhinotermitidae). Sociobiology 28:103-110 
Holway DA, Lach L, Suarez AV, Tsutsui ND, Case TJ (2002) The causes and consequences of ant invasions. Annu Rev Ecol Syst 33:181-233

Huang LW, Chen LL (1984) Biology and colony development of Coptotermes formosanus Shiraki. Acta Entomol Sin 27:64-69

Husseneder C, Grace JK (2001) Evaluation of DNA fingerprinting, aggression tests, and morphometry as tools for colony delineation of the Formosan subterranean termite. J Insect Behav 14:173-186

Husseneder C, Brandl R, Epplen C, Epplen JT, Kaib M (1998) Variation between and within colonies in the termite: morphology, genomic DNA, and behaviour. Mol Ecol 7:983-990

Husseneder C, Messenger MT, Su NY, Grace JK, Vargo EL (2005) Colony social organization and population genetic structure of an introduced population of Formosan subterranean termite from New Orleans, Louisiana. J Econ Entomol 98:1421-1434

Husseneder C, Simms DM, Ring DR (2006) Genetic diversity and genotypic differentiation between the sexes in swarm aggregations decrease inbreeding in the Formosan subterranean termite. Insect Soc 53:212-219

Husseneder C, Simms DM, Riegel C (2007) Evaluation of treatment succes and patterns of reinfestation of the Formosan subterranean termite (Isoptera: rhinotermitidae). J Econ Entomol 100:1370-1380

Husseneder C, Powell JE, Grace JK, Vargo EL, Matsuura K (2008) Worker size in the Formosan subterranean termite in relation to colony breeding structure as inferred from molecular markers. Environ Entomol 37:400-408

Husseneder C, Ho H-Y, Blackwell M (2010) Comparison of the bacterial symbiont composition of the Formosan subterranean termite from its native and introduced range. Open J Microbiol 4:53-66

Jenkins TM, Dean RE, Forschler BT (2002) DNA technology, interstate commerce, and the likely origin of Formosan subterranean termite (Isoptera: Rhinotermitidae) infestation in Atlanta, Georgia. J Econ Entomol 95:381-389

Jensen J, Bohonak A, Kelley S (2005) Isolation by distance, web service. BMC Genet 6:13

Johnson RN, Starks PT (2004) A surprising level of genetic diversity in an invasive wasp: Polistes dominulus in the northeastern United States. Ann Entomol Soc Am 97: $732-773$

Kistner DH (1985) A new genus and species of Termitophilous aleocharinae from mainland China associated with Coptotermes formosanus and its zoogeographic significance (Coleoptera: Staphylinidae). Sociobiology 10:93-104

Korman AK, Pashley DP (1991) Genetic comparisons among US populations of Formosan subterranean termites. Sociobiology 19:41-50

Krieger MJB, Keller L (1997) Polymorphism at dinucleotide microsatellite loci in fire ant Solenopsis invicta populations. Mol Ecol 6:997-999

Krieger MJB, Keller L (1999) Low polymorphism at 19 microsatellite loci in a French population of Argentine ants (Linepithema humile). Mol Ecol 8:1078-1080

LaFage JP (1987) Practical considerations of the Formosan subterranean termite in Louisiana: a 30-year-old problem. In: Tamashiro M, Su N-Y (eds) Biology and control of the Formosan subterranean termite. College of Tropical Agriculture and Human Resources, University of Hawaii, Honolulu, HI, pp 37-42

Leniaud L, Pichon A, Uva P, Bagnères A-G (2009) Unicoloniality in Reticulitermes urbis: a novel feature in a potentially invasive termite species. Bull Entomol Res 99:1-10

Leniaud L, Dedeine F, Pichon A, Dupont S, Bagnères A-G (2010) Geographical distribution, genetic diversity and social organization of a new European termite, Reticulitermes urbis (Isoptera: Rhinotermitidae). Biol Invasions 12:1389-1402

Li G (2000) Coptotermes. In: Huang F, Zhu S, Ping Z, He X, Li G, Gao D (eds) Fauna Sinica, Insecta vol. 17: Isoptera. Science Press, Beijing, pp 299-341

Li H-F, Ye W, Su N-Y, Kanzaki N (2009) Phylogeography of Coptotermes gestroi and Coptotermes formosanus (Isoptera: Rhinotermitidae) in Taiwan. Ann Entomol Soc Am 102:684-693

Luikart G, Cornuet J-M, Allendorf FW (1998) Temporal changes in allele frequencies provide estimates of population bottleneck size. Conserv Biol 89:238-247

Maruyama M, Iwata R (2002) Two new termitophiles of the tribe Termitohospitini (Coleoptera: Staphylinidae: Aleocharinae) associated with Coptotermes formosanus (Isoptera: Rhinotermitidae). Can Entomol 134:419-432

Messenger MT, Mullins AJ (2005) New flight distance recorded for Coptotermes formosanus (Isoptera: Rhinotermitidae). Fla Entomol 88:99-100

Messenger MT, Su N-Y (2005) Colony characteristics and seasonal activity of the Formosan subterranean termite (Isoptera: Rhinotermitidae) in Louis Armstrong Park, New Orleans, Louisiana. J Entomol Sci 40:268-279

Messenger MT, Su NY, Husseneder C, Grace JK (2005) Elimination and reinvasion studies with Coptotermes formosanus (Isoptera : Rhinotermitidae) in Louisiana. J Econ Entomol 98:916-929

Muirhead JR, Gray DK, Kelly DW, Ellis SM, Heath DD, Macisaac HJ (2008) Identifying the source of species invasions: sampling intensity versus genetic diversity. Mol Ecol 17:1020-1035

Newsome AE, Noble IR (1986) Ecological and physiological characters of invading species. In: Groves R, Burdon J (eds) Ecology of biological invasions: an Australian perspective. Australian Academy of Science, Canberra, Australia, pp 1-20

Perdereau E (2010) Biologie de l'invasion d'un termite américain en France: évolution de l'organisation sociale et conséquences sur le succès invasive. Dissertation, Université François Rabelais, Tours, France

Perdereau E, Dedeine F, Christidès J-P, Bagnères AG (2010a) Variations in worker cuticular hydrocarbons and soldier isoprenoid defensive secretiions within and among introduced and native populations of the subterranean termite, Reticulitermes flavipes. J Chem Ecol 36:1189-1198

Perdereau E, Bagnères AG, Dupont S, Dedeine F (2010b) High occurrence of colony fusion in a European population of the American termite Reticulitermes flavipes. Insect Soc 57:393-402

Pimentel D, Zuniga R, Morrison D (2005) Update on the environmental and economic costs associated with alien-invasive species in the United States. Ecol Econ 52:273-288 
Piry S, Luikart G, Cornuet JM (1999) BOTTLENECK: a computer program for detecting recent reductions in the effective population size using allele frequency data. J Hered 90:502-503

Pritchard JK, Stephens M, Donnelly P (2000) Inference of population structure using multilocus genotype data. Genetics 155:945-959

Ross KG, Keller L (1998) Genetic control of social organization in an ant. Proc Natl Acad Sci USA 95:14232-14237

Sakai AK, Allendorf FW, Holt JS, Lodge DM, Molofsky J, With KA, Baughman S, Cabin RJ, Cohen JE, Ellstrand NC, McCauley DE, O'Neil P, Parker IM, Thompson JN, Weller SG (2001) The population biology of an invasive species. Annu Rev Ecol Syst 32:305-332

Scott RF, Scott HG (1996) The Formosan subterranean termite, Coptotermes formosanus. River Ridge, Louisiana. $144 \mathrm{pp}$

Shelton TG, Grace JK (1996) Review of agonistic behaviors in the Isoptera. Sociobiology 28:155-176

Shiraki T (1909) Japanese termites. Trans Entomol Soc Japan 2:229-242 (In Japanese)

Simms DM, Husseneder C (2009) Assigning individual alates of the Formosan subterranean termite to their colonies of origin within the context of an area-wide management program. Sociobiology 53:631-650

Spink WT (1967) The Formosan subterranean termite in Louisiana. Louisiana State Univ. Circ. 89, $12 \mathrm{pp}$

Su N-Y (2003) Overview of the global distribution and control of the Formosan subterranean termite. Sociobiology 41:7-16

Su N-Y, Tamashiro M (1987) An overview of the Formosan subterranean termite in the world. In: Tamashiro M, Su N-Y (eds) Biology and control of the Formosan subterranean termite. College of Tropical Agricultural and Human Resources, University of Hawaii, Honolulu, HI, pp 3-15

Su N-Y, Ye W, Ripa R, Scheffrahn RH, Giblin-Davis RM (2006) Identification of Chilean Reticulitermes (Isoptera: Rhinotermitidae) inferred from three mitochondrial gene DNA sequences and soldier morphology. Ann Entomol Soc Am 99:352-363

Suarez AV, Tsutsui ND, Holway DA, Case TJ (1999) Behavioral and genetic differentiation between native and introduced populations of the Argentine ant. Biol Invasions 1:43-53

Suarez AV, Holway DA, Tsutsui ND (2008) Genetics of colonizing species-the invasive Argentine ant. Amer Nat 172:S72-S84

Swezey OH (1914) Notes and exhibitions. Proc Hawaii Entomol Soc 3:27

Thorne BL, Traniello JFA, Adams ES, Bulmer M (1999) Reproductive dynamics and colony structure of subterranean termites of the genus Reticulitermes (Isoptera: Rhinotermitidae): a review of the evidence from behavioral, ecological, and genetic studies. Ethol Ecol Evol 11:149-169

Tsutsui ND, Suarez AV (2003) The colony structure and population biology of invasive ants. Conserv Biol 17: $48-58$

Tsutsui ND, Suarez AV, Holway DA, Case TJ (2000) Reduced genetic variation and the success of an invasive species. Proc Natl Acad Sci USA 97:5948-5953

Tsutsui ND, Suarez AV, Grosberg RK (2003) Genetic diversity, asymmetrical aggression, and recognition in a widespread invasive species. Proc Nat Acad Sci USA 100:1078-1083

Vargo EL (2000) Polymorphism at trinucleotide microsatellite loci in the subterranean termite Reticulitermes flavipes. Mol Ecol 9:817-829

Vargo EL (2003) Hierarchical analysis of colony and population genetic structure of the Eastern subterranean termite, Reticulitermes flavipes, using two classes of molecular markers. Evolution 57:2805-2818

Vargo EL, Carlson JR (2006) Comparative study of breeding systems of sympatric subterranean termites (Reticulitermes flavipes and $R$. hageni) in Central North Carolina using two classes of molecular genetic markers. Environ Entomol 35:173-187

Vargo EL, Henderson G (2000) Identification of polymorphic microsatellite loci in the Formosan subterranean termite, Coptotermes formosanus Shiraki. Mol Ecol 9:1919-1952

Vargo EL, Husseneder C (2009) Biology of subterranean termites: insights from molecular studies of Reticulitermes and Coptotermes. Annu Rev Entomol 54:379-403

Vargo EL, Husseneder C, Grace JK (2003) Colony and population genetic structure of the Formosan subterranean termite, Coptotermes formosanus, in Japan. Mol Ecol 12:2599-2608

Vargo EL, Husseneder C, Woodson WD, Waldvogel MG, Grace JK (2006) Genetic analysis of colony and population structure of three introduced populations of the Formosan subterranean termite (Isoptera: Rhinotermitidae) in the continental United States. Environ Entomol 35: 151-166

Wang J, Grace JK (2000) Genetic relationship of Coptotermes formosanus (Isoptera: Rhinotermitidae) populations from the United States and China. Sociobiology 36:7-19

Wang J, Powell J, Liu Y-Z (2002) A literature review of the biology and ecology of Coptotermes formosanus (Isoptera: Rhinotermitidae) in China. Sociobiology 40:343-360

Weir BS, Cockerham CC (1984) Estimating $F$-statistics for the analysis of population structure. Evolution 38:1358-1370

Woodson WD, Wiltz BA, Lax AR (2001) Current distribution of the Formosan subterranean termite (Isoptera: Rhinotermitidae) in the United States. Sociobiology 37:661-671

Yates JR, Tamashiro M (1990) The Formosan subterranean termite in Hawaii. Res Ext Seri 117:1-4 